\section{NHS staff's stress levels rose last year as covid pandemic took its toll}

\section{Adrian O'Dowd}

Almost half of NHS staff in England (44\%) have reported feeling unwell from work related stress, the highest rate recorded in the past five years, the latest NHS Staff Survey has shown. ${ }^{1}$

In addition, around a third of staff said that they were considering quitting their job, and a fifth indicated that they may leave the health service completely.

The NHS Staff Survey 2020 received 595270 responses (a $47 \%$ response rate) from staff at 280 NHS organisations in England, from September to December 2020. The survey has been carried out annually since 2003.

Results showed that $44 \%$ of all staff (and $40 \%$ of doctors) reported being ill because of work related stress-a marked increase from previous years, such as in 2019 (40\% of all staff) and 2016 (37\%).

Around a third of staff (34\%) had worked on a covid-19 specific ward or area at some time last year, and half of staff who had done so $(50 \%)$ reported feeling unwell as a result of work related stress.

Other worrying results included the fact that only $69 \%$ of minority ethnic staff said that their organisation provided equal opportunities, in contrast with $87 \%$ of white staff who said the same. Although only $13 \%$ of staff reported experiencing discrimination at work, ethnic background continued to be the most common reason given and was mentioned by $48 \%$ of staff who claimed to have experienced discrimination.

However, more positive results showed that a third of staff $(33 \%)$ said that their trust took positive action on health and wellbeing - up from $29.3 \%$ in 2019-and $60 \%$ believed that they had adequate materials, supplies, and equipment to do their work, up from $56 \%$ in the previous year's survey. Most staff $(82 \%)$ were satisfied with the quality of care they gave patients, up from 81\% in 2019.

Despite these findings the proportion of staff who said that they were considering leaving their current NHS organisation was 34\%, although this has fallen slightly from $36 \%$ in 2019. Similarly, the proportion of staff considering leaving the NHS altogether was $18 \%$, down slightly from $20 \%$ in the 2019 survey.

\section{Unprecedented times}

Rob Harwood, chair of the BMA's Consultants Committee, said that the findings underlined the intense pressure NHS staff had been under in the past year.

"As vast swathes of the country stayed at home, healthcare workers continued to go to work," he said. "Not only were many coming face to face with a deadly virus, often without adequate protection, but a large proportion were working in unfamiliar environments as they agreed to be redeployed to other roles.

"[The fact] that $44 \%$ of all staff reported being ill because of work related stress is a stark yet unsurprising figure, given all that they have been through. They have dealt with death and illness on a scale the NHS was completely unprepared for, which tragically far too often included their own friends and colleagues."

Danny Mortimer, chief executive of the NHS Confederation, which represents NHS organisations, said, "The overall picture is encouraging given the unprecedented and most challenging of times NHS staff have worked through over the past 12 months.

"There are, though, significant areas of concern, and the recent data on the continued poorer experience of ethnic minority staff starkly reminds NHS leaders that staff experience varies unacceptably in their organisations."

NHS Providers' deputy chief executive, Saffron Cordery, said, "It is not surprising that the last year has taken a major toll on the mental and physical health of staff. Much more needs to be done to improve the experience of Black, Asian, and minority ethnic staff, which is consistently worse than their white colleagues.”

Jennifer Dixon, chief executive of the health think tank the Health Foundation, said, "Today's figures show that, even before the second [pandemic] wave, NHS staff were stressed and exhausted.

With increasing dissatisfaction with pay, and significant staff shortages, skimping on salaries is likely to be a false economy."

NHS Survey Coordination Centre. NHS staff survey 2020. 11 Mar 2021 https://www.nhsstaffsurveyresults.com/?utm_campaign=301882_Staff\%20survey\%202020\%20press\%20release\&utm_medium=email\&utm_source=NHS\%20Confederation\&dm_i=6019\%2C6GXM\%2C282189\%2CQXPA\%2C1. 